\title{
CHITOSAN AND RICE STARCH FILMS AS PACKAGING MATERIALS
}

\author{
Urška Vrabič Brodnjak ${ }^{1}$, Dimitrina Todorova ${ }^{2}$ \\ ${ }^{1}$ University of Ljubljana, Faculty of Natural Sciences and Engineering, \\ Department of Textiles, Graphic Arts and Design, Ljubljana, Slovenia \\ ${ }^{2}$ University of Chemical Technology and Metallurgy, \\ Department of Pulp, Paper and Graphic Art, Sofia, Bulgaria
}

\begin{abstract}
Producers of bio-based materials are keen on replacing oil-based packaging materials with green, sustainable materials which also have improved mechanical, antimicrobial, barrier properties. One of the most nontoxic and widely used polymers are polysaccharides, chitosan being one of them.

This research shows the preparation, characterisation of the chitosan and rice starch films. The aim of the research was to improve the mechanical, moisture and optical properties of chitosan, rice starch and composite chitosan-rice starch film using ultrasonic treatment. Our research was focused on the effect of ultrasonic treatment on the solutions for the preparation of the mentioned films.

The results showed that an ultrasonic treatment improved elasticity, moisture resistance and that films were more transparent. Elongation at break and tensile strength increased, especially at blend films. Moreover, moisture content showed a decrease proportional to an increase in thickness with decreasing film solubility at all treated samples. The surface at untreated blend film was more uneven compared to chitosan and rice starch films, which improved after the treatment. However, preparing film solutions with ultrasound is an improved procedure to increase many properties of biodegradable films and in this form could be used as packaging materials.
\end{abstract}

Key words: materials, food, blend films, biodegradability, sustainability

\section{INTRODUCTION}

Producers of bio-based materials are keen on replacing oil-based packaging materials with green, sustainable materials which also have improved mechanical, antimicrobial, barrier properties (Bourtoom \& Chinnan , 2008), (Caner et al, 1998). One of the most nontoxic and widely used polymers are polysaccharides, chitosan being one of them. It is a natural polysaccharide, derived with the deacetylation of chitin (Krochta \& De Mulder-Johnston, 1997). Chitosan has also attracted interest in packaging, especially in the food packaging area as edible films and coatings (Vrabič Brodnjak, 2017). It is known that chitosan films have great mechanical properties, e.g. they are flexible, long lasting, have good strength and increase storage life of fresh food (Xu et al, 2005). They also have good barrier properties against grease due to the positive charge on the amino group under acidic conditions, where chitosan binds negatively charged molecules. Moreover, chitosan films exhibit excellent oxygen-barrier properties, due to their high crystallinity and hydrogen bonds between molecular chains (Cheng, Chen, Liu et al, 2010). On the other hand, there are many other natural polymers, which could be used as materials for packaging. One of them is also rice starch. Due to the high amount of amylase, rice starch is attractive for food packaging as a film barrier (Xu et al, 2005). It has also been used to replace plastic film barriers as it has good mechanical properties (Bourtoom \& Chinnan, 2008), (Krochta \& De Mulder-Johnston, 1997), (Xu et al, 2005). Rice is the most widely used basic food in the world. Due to different climates, soil characteristics and cultures, more than 240000 registered varieties of rice exist in the world and consequently as many different types of rice starch, (Xu et al, 2005).

This research shows the preparation, characterisation of the chitosan and rice starch films. The aim of the research was to improve the mechanical, moisture and optical properties of chitosan, rice starch and composite chitosan-rice starch film using ultrasonic treatment. Previously, no research was conducted on the blend of rice starch and chitosan film, and a subsequent improvement of the properties with ultrasound. Our research was focused on the effect of ultrasonic treatment on the solutions for the preparation of the mentioned films. Using ultrasound is an environmentally friendly process and it can be used for all solutions in order to improve biodegradable films. Such a treatment and materials could be used as a substitute for packaging films that are currently on the market.

The results showed that an ultrasonic treatment improved elasticity, moisture resistance and that films were more transparent. Elongation at break and tensile strength increased, especially at blend films. Moreover, moisture content showed a decrease proportional to an increase in thickness with decreasing 
film solubility at all treated samples. The surface at untreated blend film was more uneven compared to chitosan and rice starch films, which improved after the treatment. However, preparing film solutions with ultrasound is an improved procedure to increase many properties of biodegradable films and in this form could be used as packaging materials.

\section{METHODS}

\subsection{Materials}

Chitosan, with molecular weight 20kDa and deacetylation degree higher than 85\%, was purchased from Sigma Aldrich (Austria). Rice starch was obtained from Farmalabor Srl (Italy), with moisture content of $14 \%, 1 \%$ of proteins and $0.6 \%$ of ashes. Malic acid (98\%) was purchased from Sigma Aldrich (Austria). Glycerol, obtained from Sigma Aldrich (Austria), was also used as a plasticiser.

\subsection{Preparation of film-forming rice starch and chitosan dispersions}

The rice starch dispersion was prepared by dissolving $2 \mathrm{~g}$ of rice starch in $100 \mathrm{ml}$ of distilled water and glycerol $(40 \% \mathrm{w} / \mathrm{w})$ was added as a plasticiser. The solution was mixed until it gelatinised $\left(85{ }^{\circ} \mathrm{C}\right.$ for 20 $\min$ ) and then cooled to room temperature.

The chitosan solution was prepared by dissolving $2 \mathrm{~g}$ of chitosan in $100 \mathrm{ml}(2 \% \mathrm{w} / \mathrm{w})$ malic acid and glycerol $(40 \% \mathrm{w} / \mathrm{w})$ was added as a plasticiser. The solution was mixed at $90{ }^{\circ} \mathrm{C}$ for 5 minutes until chitosan was not dispersed and after that cooled to room temperature. Before cooling down, the film solution was filtered through a polyester screen (mesh no. 140 with mesh opening $160 \mu \mathrm{m}$ ) with aspiration to remove small lumps in the solution.

\subsection{Preparation of solution for chitosan-rice starch blend film}

The rice starch-chitosan film was prepared by mixing $100 \mathrm{ml}$ of $2 \%$ rice starch solution with $100 \mathrm{ml}$ of $2 \%$ chitosan solution. After that, $40 \%$ of glycerol as a plasticiser (w/w; of total solid weight in solution) was added into the mixed solution. The total solution for blend film was mixed at 800 rpm for 5 minutes at room temperature and then filtered through a polyester screen with the same mesh opening as at the chitosan solution. The aspiration was performed in order to remove small lumps in the solution.

After the aspiration, the solutions (for chitosan, rice starch film and blend film) were put into an ultrasonic bath (Asonic, Ultrasonic bath), using constant $35 \mathrm{kHz}$ frequency for 15 minutes (Cheng, Chen, Liu et al, 2010).

\subsection{Preparation of casting films}

After the aspiration and the treatment, the mixtures (untreated and treated) were cast onto petri dishes $(50 \mathrm{ml})$, spread thinly, uniformly and dried at $55^{\circ} \mathrm{C}$ for 10 hours. After the films were peeled off from the dishes, they were cooled at room temperature $\left(23^{\circ} \mathrm{C} ; 55 \% \mathrm{RH}\right)$. The films were stored in desiccators at $60 \% \mathrm{RH}$ for further investigations.

\subsection{Characterization of films}

\subsubsection{Film thickness}

The thickness of films was measured with a precision digital micrometre Mitutoyo Corporation, Japan, to the nearest $0.0001 \mu \mathrm{m}$ at 5 random locations on each film.

\subsubsection{Moisture content}

Moisture content was determined by measuring weight loss upon drying in a laboratory oven at $105 \pm 1{ }^{\circ} \mathrm{C}$ until constant weight. Five samples per each films were tested and the results were expressed in percentage.

\subsubsection{Water vapour permeability (WVP)}

To determine the WVP of films, the ASTM E96 standard desiccant method was used [19]. The test cups were filled with silica gel ( $\mathrm{RH}=16 \%$ in the cup), where a sample was placed between the cup and the ring 
cover of each cup [20]. There was an air gap of $11 \mathrm{~mm}$ between the silica gel and the underside of the placed film. To ensure the best results of WVP, a silicone sealant was applied around the cup edge. The films with the exposed area of $50 \mathrm{~cm}^{2}$ were tested at $90 \pm 2 \% \mathrm{RH}$ and $38 \pm 2{ }^{\circ} \mathrm{C}$ for 24 hours. Three replicas per each film were tested.

\subsubsection{Tensile properties}

Tensile strength (TS) and elongation at break (E) of the films were determined on a tensile testing machine Instron 6022. The samples were analysed in standard atmosphere $23^{\circ} \mathrm{C} \pm 1{ }^{\circ} \mathrm{C}$ of temperature and $55 \% \pm 2 \%$ of relative humidity. The cross speed head was $0.15 \mathrm{~mm} / \mathrm{s}$. The films of $6 \mathrm{~cm}$ in length and $0.7 \mathrm{~cm}$ in width were used, and a minimum of five probes for each sample was tested. During the sample stretching, several load and elongation data per second were recorded until a break of the sample occurred.

\subsubsection{Surface properties - Scanning electron microscope (SEM)}

The SEM micrographs of film surfaces were taken with a scanning electron microscope (JSM -6060 LV). The instrument was operated at $10 \mathrm{kV}$, at the magnification 400x.

\section{RESULTS AND DISCUSSION}

\subsection{Thickness, moisture content and water vapor permeability}

The thickness of films influences water vapour properties. The nature of films from biopolymers is mostly hydrophilic; therefore, the thickness influences water barrier and mechanical properties. In our research, the thickness (mean values) of films was used in the calculations for water vapour properties (TS). Table 1 presents a comparison of untreated and treated films, and it can be seen that chitosan-rice starch blend film treated with ultrasound exhibits better WVP than the untreated samples. In our research, glycerol as a plasticiser was added, whereas the ultrasonic treatment had the biggest impact on WVP (Brodnjak, 2017), (Rhim et al, 2006). Previous research has explained that chitosan films have great oxygen but poor water vapour barriers, which is due to their hydrophilic character, which was also proved in our research (Dias et al, 2010), (Butler et al, 1996).

From the obtained results, it can be seen that the best water vapour properties characterise the chitosanrice starch film treated with ultrasound $\left(3.37 \pm 0.29 \mathrm{~g} \mathrm{~mm} / \mathrm{m}^{2} /\right.$ day $\mathrm{kPa}$, i.e. is by two times lower than at the untreated sample). The same trend is detected at chitosan and rice-starch film. The WVP of untreated chitosan film decreased with the treatment from 9.11 to $8.47 \mathrm{~g} \mathrm{~mm} / \mathrm{m}^{2} / \mathrm{day} \mathrm{kPa}$.

Table 1: Results of thickness, moisture content and water vapor permeability

\begin{tabular}{|l|l|c|c|c|}
\cline { 2 - 5 } \multicolumn{1}{c|}{} & Sample & $\begin{array}{c}\text { Thickness } \\
(\mu \mathrm{m})\end{array}$ & $\begin{array}{c}\text { Moisture content } \\
(\%)\end{array}$ & $\begin{array}{c}\text { WVP } \\
\left(\mathrm{g} \mathrm{mm} / \mathrm{m}^{2} / \text { day } \mathrm{kPa}\right)\end{array}$ \\
\hline \multirow{4}{*}{ Untreated } & Chitosan film & $210 \pm 2.5$ & $11.3 \pm 0.55$ & $9.11 \pm 0.36$ \\
\cline { 2 - 5 } & Rice starch film & $205 \pm 5.0$ & $10.8 \pm 0.69$ & $6.45 \pm 0.75$ \\
\cline { 2 - 5 } & Blend film & $215 \pm 3.3$ & $9.5 \pm 0.23$ & $7.92 \pm 0.17$ \\
\hline \multirow{3}{*}{$\begin{array}{l}\text { Treated with } \\
\text { ultrasound }\end{array}$} & Chitosan film & $207 \pm 6.7$ & $10.8 \pm 0.47$ & $8.47 \pm 0.24$ \\
\cline { 2 - 5 } & Rice starch film & $203 \pm 4.2$ & $9.6 \pm 0.18$ & $5.45 \pm 0.36$ \\
\cline { 2 - 5 } & Blend film & $216 \pm 1.2$ & $9.0 \pm 0.78$ & $3.37 \pm 0.29$ \\
\hline
\end{tabular}

The presence of rice starch in blend films can form highly cross-linked systems, preventing water molecules from penetrating into composite films (Thakur et al, 2016). The values of moisture content of the untreated films were higher than of treated ones. The highest moisture content characterised the untreated chitosan film (11.03\%) and the lowest the treated blend film (9.0\%). The acoustic activation in ultrasonic bath caused differences in the tested films. In the case of addition of glycerol, at all tested films, the observed behaviour can be a consequence of an increase in free volume, and a consequent decrease in WVP and moisture content. The reason is in the high content of glycerol, which was present at all samples. The ultrasonic treatment affected all films regarding moisture absorption, with a decrease 
between 0.5 and $1 \%$. The decrease was not major, yet the impact on the solution and afterwards on other film properties was detected.

\subsection{Tensile properties}

The results of tensile strength and elongation at break of untreated and ultrasound treated films are presented in Figure 1. They demonstrated that tensile strength increased with the ultrasonic treatment at all treated films. Better results of tensile strength are at treated samples and the maximum occurred at the blend of chitosan-rice starch film. The values of untreated films are slightly higher, but still comparable to those reported in the literature (Rivero et al, 2009). The highest increase was detected at the blend of chitosan-rice starch film, i.e. by $30 \%$, and at chitosan film by $18 \%$. The treated rice starch film had a lower increase, i.e. by $4 \%$. Elongation at break (E) is an indicator for film extensibility and is determined as the point when a film breaks at tensile testing. The values of elongation at break were affected by the ultrasonic treatment. The highest elongation at break characterised blend films, which with an ultrasonic treatment increased by $8 \%$. At the rice starch and chitosan film, elongation increased by $2.5 \%$ at both samples. The values of elongation are higher at all samples due to the added plasticiser, i.e. glycerol. Nevertheless, the elongations at break was better at all treated samples also because of the increase in solubility and homogeneity of all film solutions, due to the acoustic activation in the ultrasonic bath.

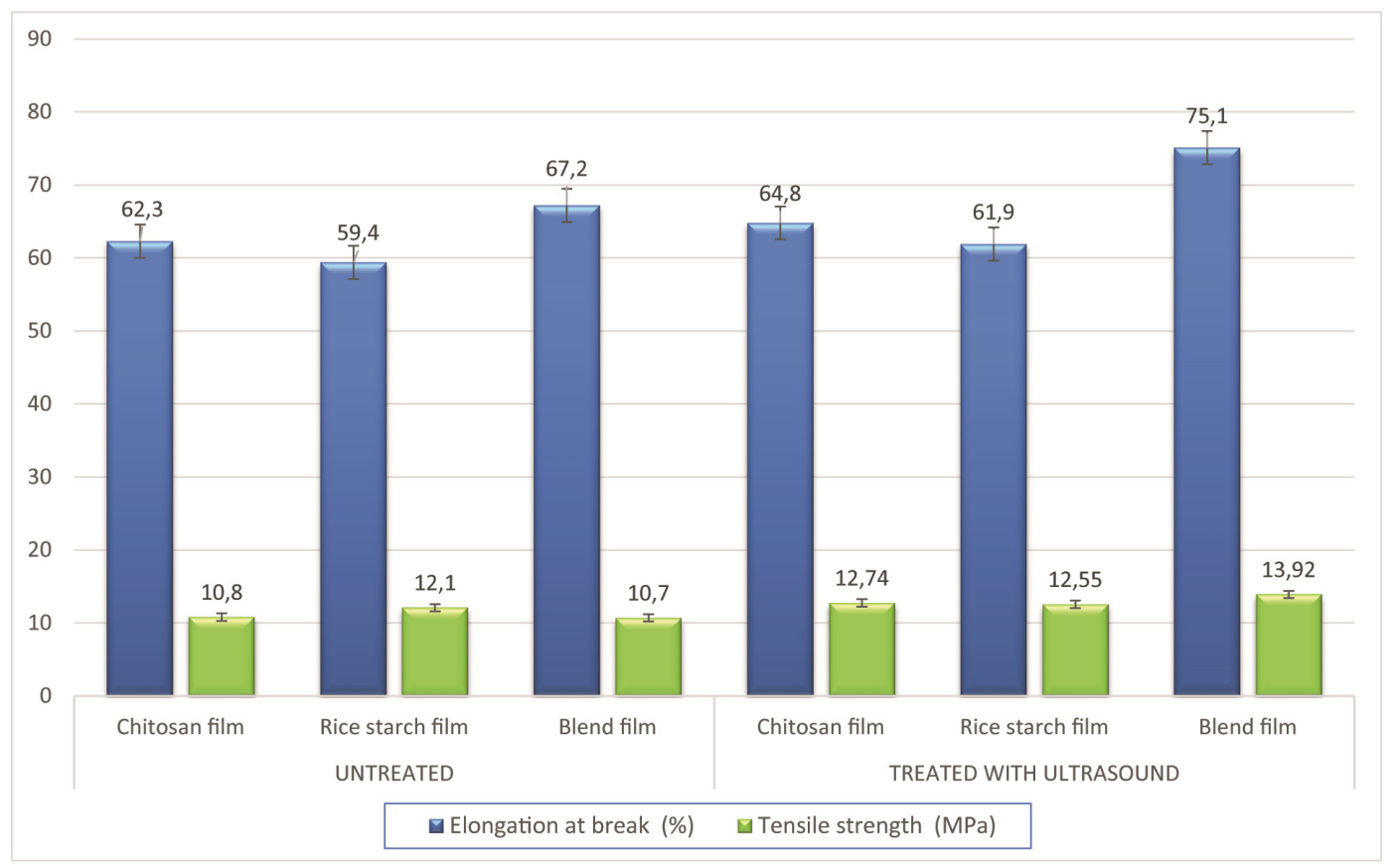

Figure 1: Tensile properties of untreated and ultrasound treated chitosan, rice starch and blend films

\subsection{Surface properties}

Surface properties were determined with scanning electron microscope (SEM) in order to analyse the effect of ultrasound treatment of film solutions on final product-packaging films. SEM micrographs of untreated and treated films are presented in Figure 2 (a-f). All figures show the surface of films at 400x magnification and voltage $10 \mathrm{kV}$. The $10 \mathrm{kV}$ voltage was used since at higher voltage, film samples would get damaged very quickly and the determination of the surface would not be correct. The same was at 400x magnification, as higher magnifications degrade the surface of analysed films.

The surface micrographs revealed a smoother, even surface at all treated films. As seen in Figure $2 a$, the untreated chitosan film is less smooth and not as even as the film treated with ultrasound (Figure 2b). The same trend is seen in Figures $2 c$ and $2 d$, where the SEM micrographs of rice starch are shown. From Figure $2 c$, it can be seen that the untreated rice starch film has a more irregular surface than the chitosan film. 

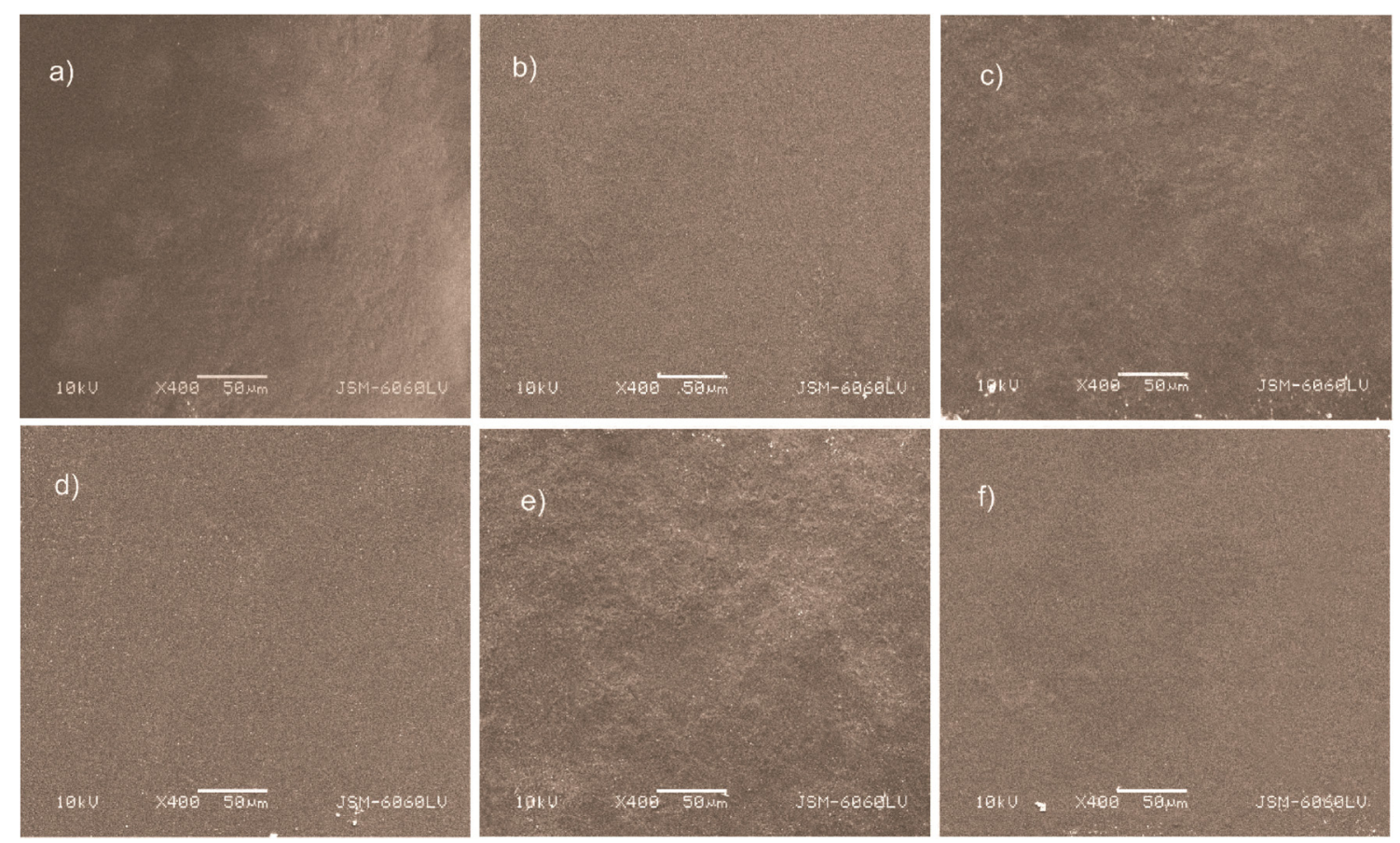

Figure 2: Surface properties of untreated and ultrasound treated films a) untreated chitosan film, b) treated chitosan film, (c) untreated rice starch film, d) treated rice starch film, e) untreated blend chitosan-rice starch film, f) treated blend chitosan-rice starch film

\section{CONCLUSIONS}

From our research and analysis we came to the conclusion that the ultrasonic treatment caused homogeneity of the surface and it is a good indicator for better structural and mechanical properties, compared to the untreated films. The surface of films improved at all treated films. The mechanical resistance of treated films was improved, especially at blend film. By mixing these two polymers, characteristics of the film improved and with an ultrasonic treatment, the properties got even better.

Nevertheless, the elongations at break were better at all treated samples also because of the increase in solubility and homogeneity of all film solutions, due to the acoustic activation in the ultrasonic bath. The results demonstrated that tensile strength increased with the ultrasonic treatment at all treated films. Better results of TS are at treated samples and the maximum occurred at the blend of chitosan-rice starch film. The presence of rice starch in blend films can form highly cross-linked systems, preventing water molecules from penetrating into composite films. Such behaviour was confirmed at our research due to the inclusion of glycerol and rice starch as well, since they interfere with cross-links, resulting in decreased water solubility.

In general, the ultrasonic treatment helps to obtain a smoother and homogeneous surface. New studies are necessary to find the best ultrasonic procedures (regarding treatment times and frequency) to prepare the films.

\section{ACKNOWLEDGMENTS}

This research was supported by the COST action CA15118 (FoodMC). The authors would like to thank University of Ljubljana, Faculty of Natural Sciences and Engineering, Department of Textiles Graphic Arts and Design, Ljubljana, Slovenia for financial support and University of Chemical Technology and Metallurgy, Department of Pulp, Paper and Printing Art in Sofia. 


\section{REFERENCES}

[1] Bourtoom, T., Chinnan, M. S.: "Preparation and properties of rice starch-chitosan blend biodegradable film", Food Science and Technology, 41(9), 1633-1641, 2008. doi: 10.1016/j.Iwt.2007.10.014

[2] Brodnjak, U. V.: "Experimental investigation of novel curdlan/chitosan coatings on packaging paper", Progress in Organic Coatings, 112, 86-92, 2017. doi: 10.1016/j.porgcoat.2017.06.030

[3] Butler, B. L., Vergano, P. L., Testin, R. F., Bunn, J. M., Wiles, J. L.: “Mechanical and barrier properties of edible chitosan film as affected by composition and storage", Journal of food Science, 61(5), 953956, 1996. doi: 10.1111/j.1365-2621.1996.tb10909.x

[4] Caner, C., Vergano, P.J., Wiles, J.L.: “Chitosan film mechanical and permeation properties as affected by acid, plasticizer, and storage", Journal of Food Science, 63(6), 1049-1053, 1998. doi: 10.1111/j.1365-2621.1998.tb15852.x

[5] Cheng, W. J., Chen, J. C., Liu, D. H., Ye, X. Q., Ke, F. S.: "Impact of ultrasonic treatment on properties of starch film-forming dispersion and the resulting films", Carbohydrate Polymers, 81(3), 707-711, 2010. doi: 10.1016/j.carbpol.2010.03.043

[6] Dias, A. B., Müller, C. M. O., Larotonda, F. D. S., Laurindo, J.: "Biodegradable films based on rice starch and rice flour", Journal of Cereal Science, 51(2), 213-219, 2010. doi: 10.1016/j.jcs.2009.11.014

[7] Rivero, S., García, M. A., Pinotti, A.: "Composite and bi-layer films based on gelatin and chitosan", Journal of Food Engineering, 90(4), 531-539, 2009. doi: 10.1016/j.jfoodeng.2008.07.021

[8] Rhim, J. W. , Hong, S. I. , Park, H. M. , Perry, K. W. N.: "Preparation and characterization of ChitosanBased Nanocomposite Films with Antimicrobial Activity", Journal of Agricultural and Food Chemistry, 54(16), 5814-5822, 2006. doi: 10.1021/jf060658h

[9] Krochta, J.M., De Mulder-Johnston, C.: "Edible and biodegradable polymer films: challenge and opportunities", Food Technology, 51, 61-74, 1997.

[10] Thakur, R., Saberi, B., Pristijono, P., Golding, J., Stathopoulos, C., Scarlett, C., Vuong, Q.: "Characterization of rice starch-ı-carrageenan biodegradable edible film. Effect of stearic acid on the film properties", International journal of biological macromolecules, 93(Pt A), 2016. doi: 10.1016/j.ijbiomac.2016.09.053

[11] Vrabič Brodnjak, U.: "Influence of ultrasonic treatment on properties of bio-based coated paper", Progress in organic coatings, 103, 93-100, 2017. doi: 10.1016/j.porgcoat.2016.10.023

[12] Xu, X.Y., Kim, K.M., Hanna, M. A., Nag, D.: “Chitosan-starch composite film: preparation and characterization", Industrial Crops and Products, 21(2), 185-192, 2005. doi: 10.1016/j.indcrop.2004.03.002

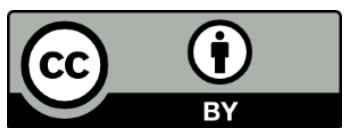

(C) 2018 Authors. Published by the University of Novi Sad, Faculty of Technical Sciences, Department of Graphic Engineering and Design. This article is an open access article distributed under the terms and conditions of the Creative Commons Attribution license 3.0 Serbia (http://creativecommons.org/licenses/by/3.0/rs/). 